\title{
PREDSUŠENJE LISTA STEVIJE (STEVIA REBAUDIANA) KAO DODATKA ZA KRMNE SMJESE UPORABOM NISKOENERGETSKOG LASERSKOG ZRAČENJA
}

\section{PREDRYING OF STEVIA LEAVES (STEVIA REBAUDIANA) AS THE FEED ADDITIVE BY USING LOW-ENERGY LASER RADIATION}

\section{A. Galić, S. Pliestić, Nadica Dobričević, Sandra Voća, Jana Šic Žlabur}

\section{SAŽETAK}

Cilj je preraditi listove stevije $\mathrm{u}$ osušeni i usitnjeni proizvod $\mathrm{u}$ svrhu dodavanja krmnim smjesama kao prirodnog zaslađivača. Ovaj rad analizira metodu predsušenja listova stevije (Stevia rebaudiana) koherentnim zračenjem (laserom) male izlazne snage u laboratorijskim uvjetima. Listovi su osvjetljivani samo s jedne strane u trajanju od $300 \mathrm{~s} 100 \mathrm{~mW}$ laserom valne duljine $655 \mathrm{~nm} \mathrm{i}$ $200 \mathrm{~mW}$ laserom valne duljine $660 \mathrm{~nm}$. Oba izvora koherentnog zračenja su u crvenom dijelu vidljivog spektra svjetlosti. Za analizu su korišteni svježe ubrani listovi stevije s udjelom vlage od $63.20 \%$.

Tretman niskoenergetskim koherentnim zračenjem $\mathrm{u}$ trajanju od 300 sekundi uzrokovao je smanjenje udjela vlage za $0.3576 \%$ kod $100 \mathrm{~mW}$ lasera i $0.3655 \%$ kod $200 \mathrm{~mW}$ lasera. Predložena metoda sušenja omogućuje brzo i učinkovito smanjenje vlažnosti pri čemu ne dolazi do oštećenja biljnog materijala. Za praktičnu primjenu predložena je izvedba sušnice s ugrađenom mrežom laserskih dioda. Tretman koherentnim zračenjem male izlazne snage predstavlja jeftinu i ekološki sigurnu metodu koja ne zagađuje okoliš te ujedno omogućuje značajne uštede u potrošnji energije.

Ključne riječi: list stevije, predsušenje, krmne smjese, laser

\section{ABSTRACT}

The goal is to process Stevia leaves into dried powder as a natural sweetener feed compound.

A laboratory laser beam drying method for Stevia leaves (Stevia rebaudiana) is presented. Leaves were illuminated on one side during a period of $300 \mathrm{~s}$ with $100 \mathrm{~mW} 655 \mathrm{~nm}$ and $200 \mathrm{~mW} 660 \mathrm{~nm}$ collimated coherent light. Both sources of coherent light were in the red part of the visible spectrum of light. 
A. Galić i sur.: Predsušenje lista stevije (Stevia rebaudiana) kao dodatka za krmne smjese uporabom niskoenergetskog laserskog zračenja

Freshly harvested Stevia leaves with $63.20 \%$ of moisture were used for the analysis. Low-energy laser beam treatment for a period of $300 \mathrm{~s}$ resulted in the reduction of moisture content of $0.3576 \%$ in $100 \mathrm{~mW}$ laser treatment and $0.3655 \%$ in the $200 \mathrm{~mW}$ laser treatment. The proposed method allows fast drying and effective reduction of humidity without causing damage to the plant material. For practical application, dryers with integrated laser diode network are proposed. Low power coherent radiation treatment represents an inexpensive and environmentally safe method that does not pollute the environment. This method also provides close control of the process, and in spite of the higher cost of energy, the overall increase in drying efficiency can bring about significant economic savings.

Keywords: Stevia leaves, predrying, feed additive, laser

\section{UVOD}

Stevia rebaudiana Bertoni je biljka iz porodice Compositae, porijeklom iz Južne Amerike i danas je vrlo rasprostranjena diljem svijeta zbog svoje ljekovitosti i slatkog okusa. Listovi biljke sadrže i veliki broj aktivnih komponenti, od kojih su najvažniji steviozid i rebaudiozid A. Steviozid i rebaudiozid sastoje se od steviola (aglikonskog dijela molekule) i određenog broja molekula glukoze (steviozid od tri molekule glukoze a rebaudiozid od četiri molekule glukoze) (Puri i sur., 2011). Zbog polarne skupine tj. ugljikohidratnog dijela molekule navedeni glikozidi pokazuju dobru topljivost $\mathrm{u}$ vodenim otopinama (Mitchell, 2006). Obje komponente u probavnom se traktu procesom hidrolize razlažu na šećere i steviol koji se apsorbira i topljiv je u mastima (Bernal i sur., 2011; Puri i sur., 2011; Renwick, 2008). Suho lišće stevije, koje se koristi u proizvodnji sladila, oko 10 do 15 puta je slađe od saharoze (Raymond, 2010) a njegove prerađevine su iznimno niske kalorične vrijednosti (Puri i sur., 2011; Kroyer, 2009; Seema, 2010). Listovi Stevije koji se koriste kao dodatak hrani, na tržištu su prisutni kao zeleni prah dobiven usitnjavanjem suhih zelenih listova (Mishra i sur., 2010) ili kao bijeli prah dobiven ekstrakcijom steviozida iz zelenog praha. Alaam (2007) navodi da je čisti steviozid 250 - 300 puta slađi od saharoze. Osim steviozida, suhi ekstrakt lista stevije sadrži i alkaloide, flavonoide, klorofile, ksantofile, hidroksicimetne kiseline (kava kiselina, klorogenska kiselina itd.), oligosaharide, slobodne šećere, aminokiseline, lipide kao i elemente u tragovima (Muanda i sur., 2010). Brojne studije pokazale su da, osim slatkoće, steviozid uz srodne spojeve, koji uključuju rebaudiozid, steviol i izosteviol, također ima brojne pozitivne zdravstvene učinke 
A. Galić i sur.: Predsušenje lista stevije (Stevia rebaudiana) kao dodatka za krmne smjese uporabom niskoenergetskog laserskog zračenja

kao antihiperglikemijsko, antihipertenzivno, protuupalno i antikancerogeno djelovanje (Chatsudthipong i sur., 2009). Priprema ekstrakta zahtijeva sušenje lista stevije do propisane vlažnosti, a proces predobrade sušenjem potrebno obaviti u što kraćem vremenu nakon berbe. Prisilno sušenje biljnog materijala zagrijanim zrakom predstavlja dominantnu metodu predobrade. Opće je poznato da uporaba topline pri tehnološkoj obradi biljnih sirovina značajno utječe na degradaciju pojedinih aktivnih komponenata a samim time $\mathrm{i}$ na smanjenje koncentracije fenolnih spojeva, vitamina $\mathrm{C}$ i antioksidativnog djelovanja. Nasuprot tome steviozid i rebaudiozid pokazuju značajnu stabilnost tijekom procesa toplinske obrade. Navedeni glikozidi zbog trodimenzionalne strukture svojih molekula također pokazuju i značajnu otpornost pri niskim $\mathrm{pH}$ vrijednostima (Abou-Arab i sur., 2010;. Mishra i sur., 2010).

Statistički podaci dobiveni analizom rada konvekcijskih sušnica pokazuju da se 20 do $60 \%$ dovedene topline koristi za isparavanje vlage, 5 do $25 \%$ za zagrijavanje materijala, 15 do $40 \%$ predstavlja toplinske gubitke s izlaznim zrakom, 3 do $10 \%$ toplinske gubitke kroz stjenke sušnice, a 5 do $20 \%$ ostale gubitke (Danilov i Leontchik, 1986). U cilju ispitivanja mogućnosti provođenja metode predsušenja $u$ što kraćem roku nakon berbe primjenom alternativnih $i$ nisko energetskih izvora energije ustanovljeno je da tretman zrna laserom male izlazne snage može dati zadovoljavajuće rezultate (Starzycki i sur., 2005; Jović, i sur., 2004; Jović, i sur., 2006). Pokusi sa sušenjem primjenom EM zračenja u bliskom infracrvenom području koje su proveli Vešnik i sur. (1991) pokazali su da biljni materijal u samo nekoliko sekundi apsorbira dovoljno energije te ju transformira u toplinsku energiju povećavajući temperaturu materijala, što rezultira otpuštanjem vlage uz dodatno prozračivanje. Dosadašnja istraživanja na laserima male izlazne snage pokazala su da njihova primjena izaziva više pozitivnih reakcija na biljnom materijalu, što pruža mogućnosti njihove široke primjene u poljoprivredi te preradi i doradi poljoprivrednih proizvoda (Galić i sur., 2014). Uporabom lasera u postupcima uklanjanja vlage nema ostataka sagorijevanja energenta, plinova i čvrstih ostataka štetnih za okoliš, a ujedno opada i potreba za energijom za transport zraka koji služi kao medij za zagrijavanje proizvoda. Također je potrebno naglasiti da se uz mogućnost uklanjanja vode u pozitivna djelovanja laserske svjetlosti ubraja i mikrobiocidno djelovanje na mikrofloru pa se istovremeno sa sušenjem materijala reducira i mikroflora. To je važan podatak jer smanjenjem broja nepoželjnih mikroorganizama smanjuje se i sama mogućnost zaraze produktima njihovog metabolizma različitog stupnja toksičnosti. Ipak, izlaganje materijala laserima veće izlazne snage može ukloniti previše vlage i time uzrokovati 
A. Galić i sur.: Predsušenje lista stevije (Stevia rebaudiana) kao dodatka za krmne smjese uporabom niskoenergetskog laserskog zračenja

ozbiljna oštećenja. Treba imati na umu da pojedine poljoprivredne kulture zbog različitog sastava i građe ne raspršuju snop laserskog svjetla na isti način. Stoga je nužno istražiti i pronaći ravnotežu između izlazne snage lasera, fokusiranja laserskog snopa i biološkog efekta procesa. Potrebno je napomenuti da primjena lasera male izlazne snage stvara povoljne uvjete za automatizaciju vođenja i kontrolu procesa, te da upotreba te tehnologije nema štetnog utjecaja na okoliš. Ipak, pri rukovanju laserima veće izlazne snage postavlja se pitanje mjera sigurnosne zaštite, zbog toga što laserska svjetlost iznad vrijednosti od $1 \mathrm{~mW}$ može trajno oštetiti ljudsko oko i utjecati na pravilan vid.

\section{MATERIJALI I METODE}

$\mathrm{Za}$ analizu su korišteni svježe ubrani listovi stevije s početnim udjelom vlage od $63.20 \%$. Početna vlaga materijala određena je prema standardnoj metodi AOAC (1990), u laboratorijskoj sušnici (INKO ST40T) na $105^{\circ} \mathrm{C}$ na atmosferskom tlaku tijekom $90(60+30)$ minuta do stalne mase. Od branja do procesa sušenja protekla su približno dva sata. Ispitivani listovi bili su očišćeni od nečistoća i primjesa, a u postupak su uzeti samo vizualno cijeli, zdravi i neoštećeni listovi. Čišćenje je obavljeno ručno, s ciljem da se spriječi energetski rasap do kojeg bi došlo prisutnošću nečistoća. Shematski prikaz sušnice $\mathrm{s}$ integriranom mrežom laserskih dioda (3 x 5 lasera) prikazan je na slici 1 . Sušnica se sastoji od komore za sušenje (s otvorima za ulaz i izlaz zraka te kontrolnim oknom) i mjernih instrumenata (suhi i vlažni termometar te elektronička vaga). Komora za sušenje izrađena je od poliuretanskih izolacijskih panela, obostrano obloženih pocinčanim i obojanim limom, čime se postiže kvalitetna toplinska izolacija. Svi ostali elementi izrađeni su od nehrđajućeg (inox) čelika. Sušnica posjeduje mogućnost umetanja okvira načinjenog od nehrđajućeg (inox) materijala (X6CrNiTi18-10) ukupne površine $0.25 \mathrm{~m}^{2}$, deltoidnog oblika otvora i aktivne prostrujne površine $75 \%$. Materijal izrade omogućava zadovoljavanje svih higijenskih standarda i lako čišćenje. Sve značajke procesa (temperatura, relativna vlažnost zraka, promjena mase materijala) očitavaju se na digitalnom zaslonu. 
A. Galić i sur.: Predsušenje lista stevije (Stevia rebaudiana) kao dodatka za krmne smjese uporabom niskoenergetskog laserskog zračenja

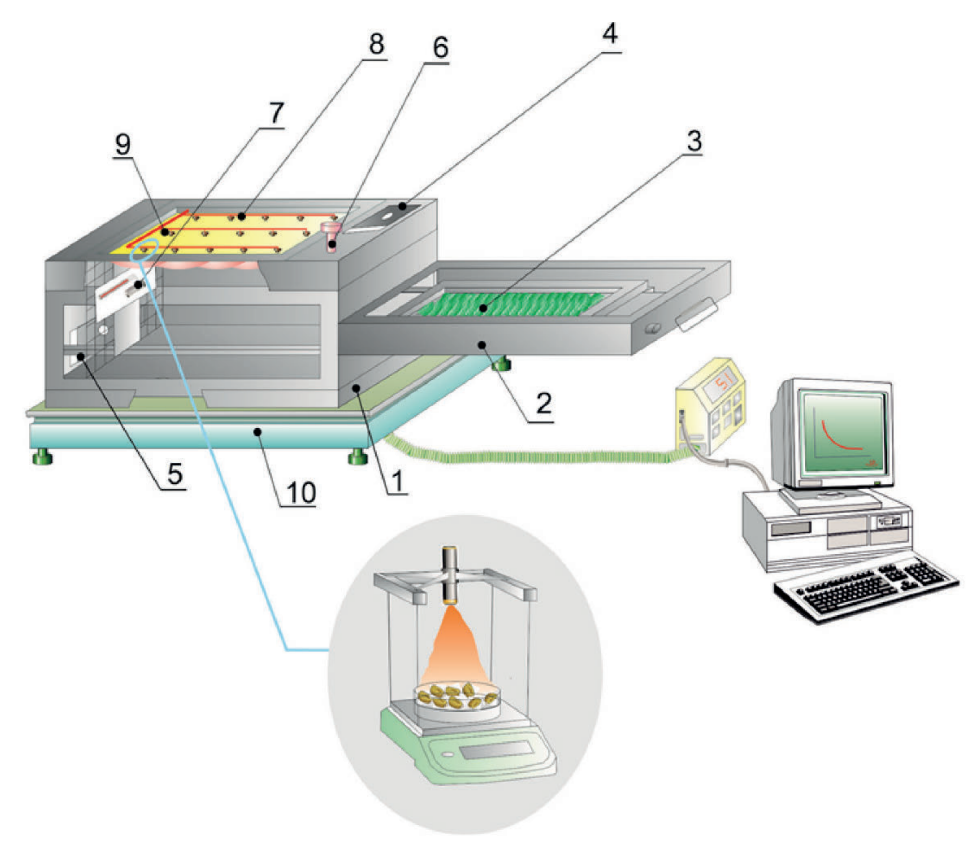

Slika 1. Shematski prikaz sušnice s integriranom mrežom laserskih dioda (gdje su: 1 -sušnica, 2 -ladica za biološki materijal, 3 -listovi stevije, 4-otvor za izlaz zraka, 5 - otvor za ulaz zraka, 6 - termometar (suhi), 7 -termometar (vlažni),

8-kontrolno okno, 9-mreža laserskih dioda, 10 - elektronička vaga)

Figure 1 Experimental set-up of the drying process illumination with laser beam (where: 1 -dryer, 2 -frame for biological material, 3 - biological material (stevia leaves), 4 -air output, 5 -air input, 6 -thermometer (dry), 7 -thermometer (wet), 8 -inspection window, 9 -laser diode net, 10 -electronic balance).

Laboratorijski testovi provedeni su na jednom segmentu mreže laserskih dioda. Pokus je postavljen, kako je navedeno na slici 2 (Nenadić i sur., 2008; Galić i sur., 2010). Listovi stevije koji su korišteni u ovom istraživanju tretirani su dvama izvorima koherentne svjetlosti (laserima) različite izlazne snage (modeli: HLM1845 maksimalne snage $100 \mathrm{~mW}$ valne duljine $655 \mathrm{~nm}$ i HLP18130 maksimalne snage $200 \mathrm{~mW}$ valne duljine $660 \mathrm{~nm}$ ). Dva glavna elementa opreme za provođenje laserskog tretmana zrnatog materijala su izvor koherentne svjetlosti i mikroobjektiv sastavljen od dvije optičke leće čime se postiže širenje laserske zrake. Širenje svjetlosti ne smije biti preveliko već kontrolirano u izračunatom radijusu snopa, jer bi u suprotnom moglo doći do smanjenja izlazne snage. Listovi 
A. Galić i sur.: Predsušenje lista stevije (Stevia rebaudiana) kao dodatka za krmne smjese uporabom niskoenergetskog laserskog zračenja

stevije tretirani su pozicionirani u elementarnom sloju direktno ispod raspršenog snopa koherentne svjetlosti unutar osvijetljenog područja promjera $10 \mathrm{~cm}$. Kontroliranjem vremena izloženosti materijala koherentnom svjetlu direktno možemo kontrolirati količinu energije koju on može primiti (absorbirati).

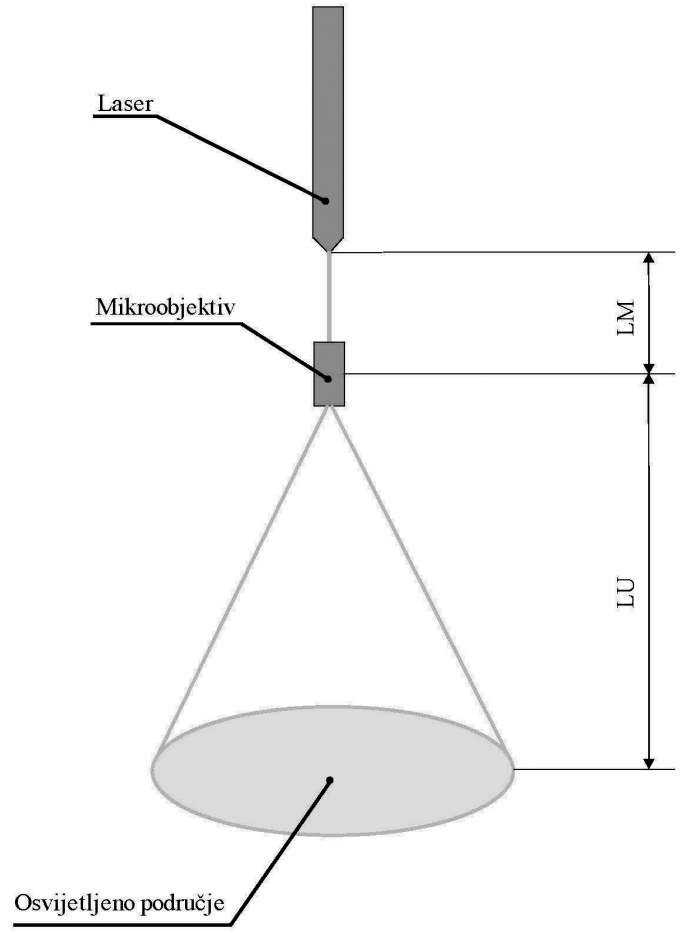

Slika 2. Smještaj izvora koherentne svjetlosti i položaj mikroobjektiva

Figure 2 Experimental set-up of the grain drying process illumination with laser beam

Udaljenost između izvora lasera i mikroobjektiva (LM) je $7 \mathrm{~cm}$, a udaljenost između mikroobjektiva i zrnja je $32 \mathrm{~cm}$. Listovi su tretirani samo s jedne strane $\mathrm{u}$ kontroliranom vremenskom intervalu od $300 \mathrm{~s}$. Vrijeme trajanja tretmana mjereno je elektroničkim kronometrom. Listovi stevije postavljeni su na laboratorijsku analitičku vagu Sartorius BP 221S (Göttingen, Njemačka) s razredom točnosti mjerenja I i podjeljkom ljestvice od $0.1 \mathrm{mg}$. Mjerenjem promjene mase tijekom tretmana određena je količina isparene vode. Tijekom procesa sušenja relativna vlažnost zraka u laboratoriju iznosila je $72 \%$, a atmosferski pritisak oko $1015 \mathrm{hPa}$. 
A. Galić i sur.: Predsušenje lista stevije (Stevia rebaudiana) kao dodatka za krmne smjese uporabom niskoenergetskog laserskog zračenja

\section{REZULTATI I RASPRAVA}

Površina osvijetljenog područja promjera $10 \mathrm{~cm}$ iznosi:

$$
\mathrm{A}=r^{2} \pi=7.85 \times 10^{-4} \mathrm{~m}^{2}
$$

Izračun predane energije unutar osvijetljenog područja za laser od $100 \mathrm{~mW}$ može se izračunati primjenom sljedeće jednadžbe:

$$
\frac{E_{\text {lasera }}}{\text { Osvijetljena površina }}=\frac{0.1 \mathrm{Watt}}{0.00785 \mathrm{~m}^{2}} \times T=12.74 \frac{\mathrm{W}}{\mathrm{m}^{2}} \times T
$$

gdje je:

$\mathrm{T}$ - vrijeme trajanja tretmana (s)

Isti izračun se može primijeniti za $200 \mathrm{~mW}$ laser pri čemu energija predana osvijetljenom području iznosi $25.48 \mathrm{Wsm}^{-2}$. Energija i broj fotona može se odrediti povezivanjem jednadžbi (Jović i sur. 2006):

$$
h v=m c^{2}
$$

gdje je:

$v$ - frekvencija fotona $=4.61538 \times 10^{15} \mathrm{~s}^{-1}$ za poluvodički laser

$\mathrm{c}$ - brzina svjetlosti $=2.99 \times 10^{8} \mathrm{~ms}^{-1}$

$\lambda$ - valna dužina fotona

Energija fotona poluvodičkog lasera iznosi:

$$
E=h v=\frac{h c}{\lambda}=3.05815 \times 10^{-18} \mathrm{~J} / \text { foton }
$$

Iz navedenog slijedi da broj fotona iznosi:

$$
\begin{gathered}
n_{100 \mathrm{~mW}}=\frac{E_{\text {lasera }}}{E_{\text {fotona }}}=\frac{0.1}{3.05815 \times 10^{-18}}=3.27 \times 10^{16} \text { fotona } / \mathrm{s} \mathrm{za} 100 \mathrm{~mW} \text { laser } \\
n_{200 \mathrm{~mW}}=\frac{0.2}{3.05815 \times 10^{-18}}=6.54 \times 10^{16} \text { fotona } / \mathrm{s} \text { za } 200 \mathrm{~mW} \text { laser }
\end{gathered}
$$

Dozračeni fotoni stvaraju ukupnu silu od:

$$
\begin{aligned}
& F_{100 \mathrm{~mW}}=n_{100 \mathrm{~mW}} \times P=6.66 \times 10^{-11} \mathrm{~N} \text { za } 100 \mathrm{~mW} \text { laser } \\
& F_{200 \mathrm{~mW}}=n_{200 \mathrm{~mW}} \times P=1.33 \times 10^{-10} \mathrm{~N} \text { za } 200 \mathrm{~mW} \text { laser }
\end{aligned}
$$


A. Galić i sur.: Predsušenje lista stevije (Stevia rebaudiana) kao dodatka za krmne smjese uporabom niskoenergetskog laserskog zračenja

Iz rezultata je vidljivo da je količina energije koju odaju odabrani laseri relativno mala, stoga je i njihov termalni utjecaj zanemariv pa se može zaključiti da se njegovo djelovanje na biljni materijal temelji isključivo na biostimulaciji. Početna vlažnost listova stevije kretala se u rasponu od 62.17 do $65.22 \%$ (vlažna baza), u prosjeku je iznosila $63.20 \%(\mathrm{n}=6)$.

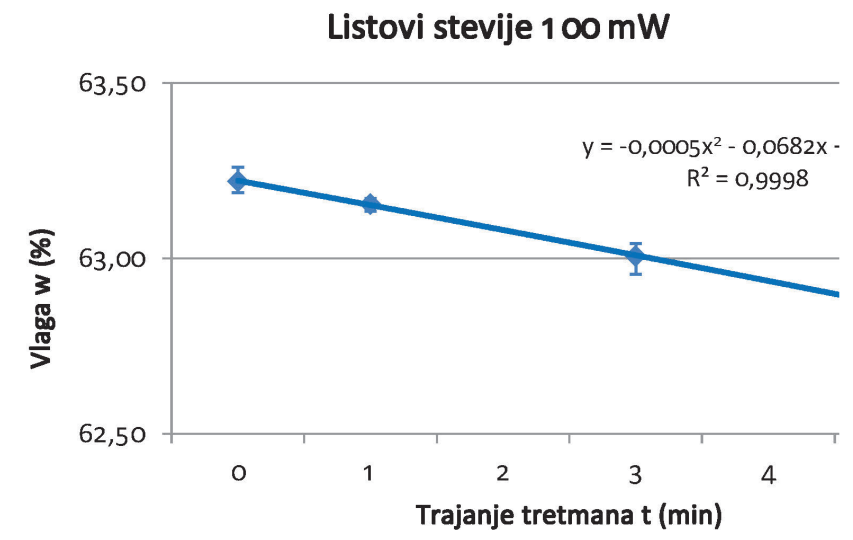

Slika 3. Utjecaj $100 \mathrm{~mW}$ laserskog zračenja na sadržaj vlage listova stevije

Fig. 3 Effect of $100 \mathrm{~mW}$ laser illumination on moisture content of stevia leaves

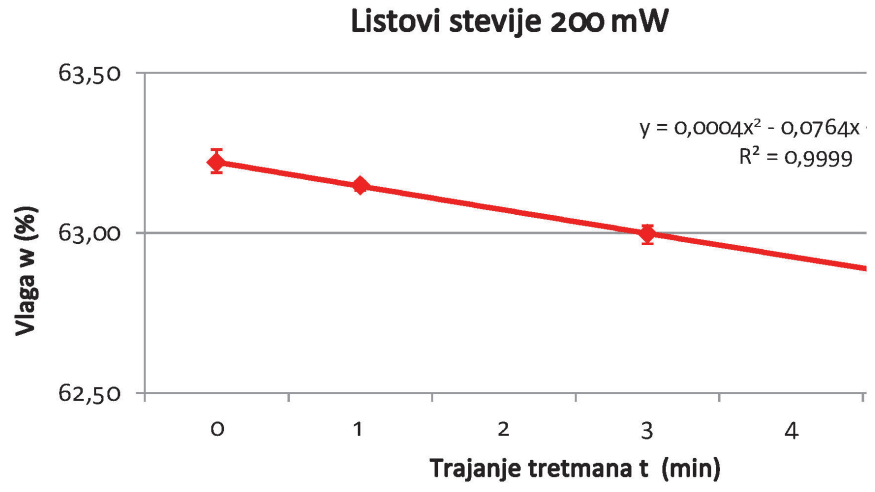

Slika 4. Utjecaj $200 \mathrm{~mW}$ laserskog zračenja na sadržaj vlage listova stevije

Fig. 4 Effect of $200 \mathrm{~mW}$ laser illumination on moisture content of stevia leaves 
A. Galić i sur.: Predsušenje lista stevije (Stevia rebaudiana) kao dodatka za krmne smjese uporabom niskoenergetskog laserskog zračenja

Poznato je da interakcija između koherentne svjetlosti i biljnog materijala ovisi o primijenjenoj frekvenciji (valnoj duljini) EM zračenja, građi listova i sadržaju vlage u njima. Na osnovi izmjerenih podataka o udjelu vlage u uzorcima pri navedenim vremenima tretiranja izračunate su polinomne jednadžbe II. reda kao model otpuštanja vode za svaku istraživanu izlaznu snagu lasera (slike 3 i 4). Sušenje primjenom $100 \mathrm{~mW}$ lasera odvija se prema jednadžbi $\mathrm{MC}=-0.0005 \tau^{2}-0.0682 \tau+63.29$ uz vrlo visoki koeficijent determinacije $\mathrm{R}^{2}=0.9998$. Sušenje primjenom $200 \mathrm{~mW}$ lasera odvija se prema jednadžbi $\mathrm{MC}=-0.0004 \tau^{2}-0.0764 \tau+63.297 \mathrm{uz}$ također vrlo visoki koeficijent determinacije $\mathrm{R}^{2}=0.9999$. Derivacijom polinomnih jednadžbi II. reda određeni su nagibi krivulja sušenja listova stevije i dobiveni su sljedeći izrazi: MC' = $0.001 \tau-0.0682$ za $100 \mathrm{~mW}$ laser i MC' $=-0.0008 \tau-0.0764$ za $200 \mathrm{~mW}$. Derivacije jednadžbi negativnog su predznaka, što ukazuje na padajuću funkciju, a potvrđuje da se radi o procesu sušenja materijala čiji je primarni cilj smanjenje količine vode unutar zrna. Iz derivacija je također vidljivo da se nagibi krivulja sušenja uzoraka, ovisno o načinu tretmana, međusobno razlikuju. Usporedbom navedenih jednadžbi, odnosno njihovih koeficijenata, pouzdano se može zaključiti da primjenom $100 \mathrm{~mW}$ lasera dolazi do nešto bržeg otpuštanja vode iz materijala.

\section{ZAKLJUČAK}

Eksperimenti su pokazali da se laser male izlazne snage može koristiti u procesu predsušenja listova stevije. Tretman niskoenergetskim laserskim snopom u trajanju od $300 \mathrm{~s}$ uzrokovao je smanjenje udjela vlage za $0.3576 \%$ kod $100 \mathrm{~mW}$ lasera i $0.3655 \%$ kod $200 \mathrm{~mW}$ lasera. Može se zaključiti da primjena lasera male izlazne snage predstavlja jeftinu i ekološki sigurnu metodu koja ne zagađuje okoliš te ujedno omogućuje značajne uštede u potrošnji energije. Također, primjena navedene metode stvara povoljne uvjete za automatizaciju vođenja i kontrolu procesa.

\section{LITERATURA}

1. Abou-Arab A. E., Abou-Arab A. A., Abu-Salem M. F. (2010.): Physico-chemical assessment of natural sweeteners steviosides produced from Stevia rebaudiana Bertoni plant. African Journal of Food Science 4 (5): 269- 281.

2. Alaam A. I. (2007.): Sugar crops council: Future view. The Proceeding of Thirtyeight Annual Conference, Egyptian Sugar Expertese Society Hawamdia, Egypt. 
A. Galić i sur.: Predsušenje lista stevije (Stevia rebaudiana) kao dodatka za krmne smjese uporabom niskoenergetskog laserskog zračenja

3. Bernal J., Mendiola J., Ibáñez E., Cifuentes A. (2011.): Advanced analysis of nutraceuticals. Journal of Pharmaceutical and Biomedical Analysis 55 (4): 758 774.

4. Chatsudthipong, V., Muanprasat, C. (2009.): Stevioside and related compounds: Therapeutic benefits beyond sweetness, Pharmacol. Therapeut. 121: 41-54.

5. Danilov O. L., Leontchik B. I. (1986.): Energy Economic in Thermal Drying Energoatomizdat, Moscow.

6. Galić, A., Nenadić, K., Pliestić, S., Jović, F. (2010.): A nonlinear impact of low energy laser beam on corn kernel drying. Third IFAC International Conference Agricontrol, 3, 1. Kyoto, Japan.

7. Galić, A., Pliestić, S., Jović, F., Nenadić, K., Jović, A. (2014.): An energy efficient corn grains drying process, Tehnički vjesnik, 21 (6), 1395-1401.

8. Jović, F., Nenadić, K., Drezner, G., Kovačević, J., Dvojković K., (2006.): Visible Wavelength Laser Beam Treatmant of Wheat Grain. In: Proceedings M4PL19. Igls/Innsbruck.

9. Jović, F., Pliestić, S., Kolak, I., Jagnjić, Ž., Blažević D. (2004.): Estimation of the laser beam scattering in food grain preprocessing. In: Proceedings of M4PL17, Igls/Innsbruck.

10. Kroyer G. (2009). Stevioside and Stevia-sweetener in food: application, stability and interaction with food ingredients. Journal of Consumer Protection and Food Safety, DOI 10.1007/s00003-010-0557-3.

11. Mishra P., Singh R., Kumar U., Prakash V. (2010.): Stevia rebaudiana - A magical sweetener. Global Journal of Biotecnology \& Biochemistry, 5: 62-74.

12. Muanda, F., Soulimani, R., Diop, B., Dicko, A. (2010.): Study on chemical composition and biological activities of essential oil and extracts from Stevia rebaudiana Bertoni leaves, LWT - Food Sci. Tec. (2010).

13. Nenadić, K., Jović, F., Pliestić, S. (2008.): An Investigation of Automatic Treatment of Seeds With Low Power Laser Beam. Automatics, 49 (3-4): 127-134.

14. Puri M., Sharma D., Tiwari A.K. (2011.): Downstream processing of stevioside and its potential applications, Biotechnology Advances, 29: 781-791.

15. Renwick, A. G. (2008.): The use of a sweetener substitution method to predict dietary exposures for the intense sweetener rebaudioside A. Food Chem. Tox. 46: $61-69$.

16. Seema T. (2010.): Stevia rebaudiana: A medicinal and nutraceutical plant and sweet gold for diabetic patients. International Journal of Pharmacy \& Life Sciences, 8: 451-457. 
A. Galić i sur.: Predsušenje lista stevije (Stevia rebaudiana) kao dodatka za krmne smjese uporabom niskoenergetskog laserskog zračenja

17. Starzycki, M.; Rybinski, W., and Other (2005.): Laser Light as a Physical Factor Enhancing Rapeseed Resistance to Blackleg Disease. Acta Agrophysica, 5 (2), 441-446.

18. Vešnik, F., Ritz, J., Dobričević, N. (1991.): Primjena infra crvenih zraka u sušenju i doradi poljoprivrednih proizvoda. Zbornik radova VII Međunarodno savjetovanje tehnologa sušenja i skladištenja, Tuheljske Toplice, 140-148.

\section{Adrese autora - Authors' addresses:}

Doc. dr. sc. Ante Galić, e-mail: agalic@agr.hr

Prof. dr. sc. Stjepan Pliestić, e-mail: spliestic@agr.hr

Prof. dr. sc. Nadica Dobričević, e-mail: ndobricevic@agr.hr

Izv. prof. dr. sc. Sandra Voća, e-mail: svoca@agr.hr

Doc. dr. sc. Jana Šic Žlabur, e-mail: jszlabur@agr.hr

Sveučilište u Zagrebu, Agronomski fakultet Svetošimunska cesta 25, 10000 Zagreb
Primljeno - Received:

15.04.2017. 
